Sustainability 2009, 1, 1012-1022; doi:10.3390/su1041012

\title{
Sustainable Development in Northern Africa: The Argan Forest Case
}

\section{Zoubida Charrouf ${ }^{1}$ and Dom Guillaume ${ }^{2, *}$}

1 Laboratoire de Chimie des Plantes, Faculté des Sciences, Université Mohammed V-Agdal, BP1014, Rabat, Morocco; E-Mail: zcharrouf@menara.ma

2

CNRS-UMR6229, 51 Rue Cognacq Jay, 51100 Reims, France

* Author to whom correspondence should be addressed; E-Mail: dominique.guillaume@univ-reims.fr

Tel.: +33-326-918-473; Fax: +33-326-918-029.

Received: 27 August 2009 / Accepted: 6 November 2009 / Published: 9 November 2009

\begin{abstract}
The argan tree is a slow growing tree exclusively endemic in the dry lowlands of Southwest Morocco. The argan forest constitutes a long time ignored specific biotope that has been declared a Biosphere Reserve by UNESCO in 1998. The argan forest is particularly fragile to climate change. Forecasts show annual precipitation levels and prolonged drought periods that could severely threaten the future of the argan forest. In some places, the argan forest is already damaged, resulting in the retreat of the argan tree and the subsequent desert encroachment. An acceleration of this trend would have devastating consequences. In response, some twenty years ago, an ambitious, unique in Northern-Africa, and government-supported program was initiated in Morocco to rescue the argan tree via the sustainable development of the argan forest. Because in the late 1980s, sustainable development in developing countries was often considered as a utopia, the argan forest case represents a sign of progress, as it is also an interesting and unique experience in Africa. This review analyses the process followed, the measures taken, the pitfalls encountered, and the results obtained during the last two decades. It also points out the measures that still need to be taken before declaring the argan forest rescue mission is accomplished.
\end{abstract}

Keywords: argan forest; argan oil; Amazigh; woman cooperative; Morocco 


\section{Introduction}

In Northern Africa, the High Atlas mountain range extends for almost 2,000 kilometers from Morocco to Tunisia. In Morocco, the western part of the mountain range stretches out from the Atlantic Ocean and its southern slopes in Algeria and Tunisia fall almost directly to the Sahara Desert. Also south of the High Atlas, but exclusively in Morocco, an additional mountain range named the Anti-Atlas extends from the Atlantic Ocean toward the Northeast. At about $30^{\circ}$ North latitude, this mountain range isolates and leads to the Souss valley. This area of $4,150 \mathrm{~km}^{2}$, quite efficiently protected from the direct effects of the Sahara desert, is opened onto the Atlantic Ocean. Its climate is moderated by maritime currents, principally the current of the Canaries. Therefore, the Souss valley constitutes a unique biotope with a macaronesian-like climate prevalent in its most oceanic part and a semi-arid to mostly arid climate dominating on the slopes of the Anti-Atlas range. Annual average temperature is $14{ }^{\circ} \mathrm{C}$ in the Northern part and reaches $20{ }^{\circ} \mathrm{C}$ in the Southern region, with daily temperatures possibly going from $-3{ }^{\circ} \mathrm{C}$ to $49{ }^{\circ} \mathrm{C}$. The average annual rainfall is $280 \mathrm{~mm}$ but presents a large geographic variability, from 50 to $500 \mathrm{~mm} /$ year. Evaporation is high, up to $1,400 \mathrm{~mm}$ in the mountainous regions and $2,000 \mathrm{~mm}$ in the plain, principally due to the chergui, a particularly hot and easterly wind. Wind- and water-induced soil degradation varies from 340 to 660 tons $/ \mathrm{km}^{2} /$ year. Because of these combined climatic and geologic factors, the Souss valley and its surrounding mountains constitute an exceptional area, where the argan tree is exclusively endemic [1]. For all these reasons, the argan forest has been declared a Biosphere Reserve by UNESCO in 1998.

The argan tree [Argania spinosa (L.) Skeels; Sapotaceae] is an 80-million-year-old relic tree species that has been known since the time of the Phoenicians, who established trade centers throughout the Mediterranean Sea and along the coast of Morocco in 600 BC. It is generally accepted that all argan trees disappeared from Northern Africa during the Quaternary glaciations, except in the Souss valley where optimum conditions for the trees' survival remained [2]. The argan tree is the only species of the family Sapotaceae that grows in the subtropical zone.

The argan forest covers about $8,280 \mathrm{~km}^{2}$, mostly in the dry lowlands of the Souss valley and on the sunny mountain spurs of the Anti-Atlas. The argan tree grows very slowly. It takes fifteen years to mature. But it is extremely resistant. Argan trees can live for 150 years, and sometimes more than 200 years, and beause of its deep root system, it can survive long periods of drought [2,4]. Therefore, the argan tree is often the ultimate warrior when the desert is encroaching on the Souss valley.

On an ecologic and economic standpoint, the argan tree 1) stabilizes the soil, reduces erosion, maintains moisture in the air, shelters a large variety of small and wild animals, and 2) shades domestic cultures and furnishes via its fruit the major part of the argan forest dwellers lipid diet. The quasi-symbiotic development between the Souss valley, the argan forest and its dwellers has resulted in an equilibrated rural micro-society that has been lasting for centuries but that is totally dependent on the argan tree.

Unfortunately, alarming signs have shown up in the argan forest; during the twentieth century its area has been reduced by half and, in some places, tree density is $66 \%$ lower than it was 50 years ago $[5,6]$. Consequently, if no measures were taken, anticipated climate change would have accelerated this dramatic trend, and the argan tree would be severely endangered with subsequent irreversible desertification of the major part of the Souss valley. To curb this trend, a vast Moroccan 
Government-supported program implemented, in association with the University Mohammed V-Agdal and aimed at safeguarding the argan forest, was initiated some twenty years ago and has been going on since then. Sustainable development of the argan forest emerged as a realistic issue capable of rescuing the argan forest, the Souss valley, and its dwellers. Soon after the beginning of the project, some private, governmental, non-governmental organizations (NGOs), and donors convinced by this program have accepted to bring some funds and/or their expertise. Among the donorss, IDRC (International Development Research Centre, Canada), and Oxfam-Québec were particularly helpful. The governments of Monaco, UK, Japan, through their respective embassies accepted to financially participate in this program, according not only the much needed finance but also an international recognition.

Sustainable development is aimed at preserving biodiversity and respecting and improving livelihoods of rural communities. It has been defined as requiring the simultaneous achievement of environmental, economic, institutional and social sustainability [7]. However, designing then managing a sustainable development program in a rich or in developing country requires two different approaches. Basically, in rich and well-structured countries, program designers generally assum that once the program has been explained and approved by the population, government agencies will be able to develop it in a quite independent manner. Efforts (financial, brief discomfort...), often equally shared by several portions of the population, will be tolerated if long-term global benefits can be reasonably anticipated for the major part of the population. Program managers will be responsible for smoothing or solving the unanticipated difficulties and make sure that the program proceeds to its end. In remote areas of developing countries, when survival is sometimes a major problem for the poorest, when income reduction often means taking girls out of school, environmental issues are not a priority. Such issues will be considered only if one can ensure that revenue derived from imposed changes is funneled back into local communities. Disconnecting environmental concerns from basic economic matters inevitably leads to the failure of the development program; poor population evaluating success only in term of short-term improvement of their daily condition.

In the case of the argan forest, the efforts necessary for the long-term rescue of the argan tree obviously necessitated an active support from the majority of its dwellers as they were also asked to modify their way life. In the mean time, little or none was asked from city-dwellers or those engaged in tourism-related businesses, even though these categories would also ultimately benefit from the preservation of the argan forest. Hence, it could be anticipated that the participation of the argan forest dwellers would only be gradual but would be iteratively reinforced if changes had a rapid and positive impact on the dwellers' daily income. Tangible proofs were necessary to build the confidence of the poor.

\section{Results and Discussion}

\subsection{The Argan Forest Micro-Society}

People living in the argan forest are commonly known as the Berbers. Argan forest natives prefer the name Amazigh (plural Imazighen) to Berber and consider it as more appropriate, even though this name is scarcely used, even in Morocco. Rural Amazigh families are generally poor and agriculture 
constitutes the major source of of their income. The life of any Amazigh family is strongly associated with the argan tree. Thus, access to the argan forest is strictly defined by traditional and coranic rules [1,2]. Imazighen use argan wood for heating, cooking, carpentry, construction, charcoal and tool making. Its leaves are used to feed cattle and the trees provide shelter against sun, a much sought-after environmental service especially during the hot hours of the day. People use products of the tree for dietary and medicinal purposes and also to prepare beauty products. The argan forest is affected mainly by increased pressure from human activities. During the early 1900s large quantities of charcoal were produced from the forest to satisfy the then-demands in European countries. In the mid1900s by the same demands from Northern Moroccan cities triggered a major decline in the argan forest [4]. Nowadays, the charcoal demand has shrunk considerably, but the basic problem still persists. The arable land of the Souss valley is now principally used to grow citrus fruit, and other fruits and vegetables to satisfy the tourism sector. For similar reason, around major balnear cities, argan trees are frequently removed to create space for greenhouses where fresh vegetables are produced year round. In remote mountainous regions, the argan forest is largely overgrazed. Sheep, camels, and more frequently goats freely graze and browse in the forest. These animals feed mainly on the young tree shoots, while goats also climb in the trees and eat young leaves and fruits. Given their large numbers, goats have become the major concern for conserving the argan forest. Goat graze up to six hours a day, and this may even extend during the winter months, when the herbaceous layer is depleted. During this period, argan leaves can constitute up to $68 \%$ of the goats diet [8]. Combined with other stressesstated earlier, overgrazing modifies branch growth pattern and its complexity [9] and dramatically weakens the trees.

Elsewhere in the argan forest, argan trees are sometime replaced by olive trees that produce easy-to-market olive oil. Olive oil production undoubtedly brings additional income to argan forest dwellers, but olive trees are not as well adapted to the Souss valley biotope as argan trees. Therefore, the natural regeneration cycle of the argan forest is disturbed and the forest decline may be permanent if this trend continues. In the long-term, olive trees may cause an accelerated erosion of the argan forest. This could make the poor even poorer. One could say that this state of the argan forest is brought about by the decision of the argan forest dwellers as well. Indeed, may be Imazighen have for a (too) long time considered the argan forest as a "free garden" or an "eternal gift of God" and they have simply observed its decline as a natural cycle. Nevertheless, it is understandable that for this poor population, and on a daily basis, solving immediate and vital needs appear more important than the long-term argan forest rescue even though its disappearance would hurt them dramatically. Consequently, it is difficult to blame this population for not investing and taking good care of the argan forest when it can hardly satisfy its own basic daily needs.

Once this situation was established, the sustainable development of the argan forest appeared as the only opportunity to successfully achieve its rescue and to ensure decent livelihoods for its population that is so much dependent on the forest. This simply meant securing the active participation of the local population to the task. The question thus became: how can the argan forest be rescued and how can it also concomitantly bring more incomes to the population? 


\subsection{Which of the Argan Tree Products Could Rescue the Forest?}

\subsubsection{The search for the magic bullet}

The most common myth among natural product chemists of the discovery of a natural organism (plant, fungus, microorganism...) that would contain "The Molecule" that would cure all incurable diseases, or, for the least, be the giant leap leading to the opening of a new medicinal era. Ancient and recent history provide examples to support this theory (e.g., morphine, quinine, penicillin, statins, taxol, etc; and the hunt is still going on.

From the fact that the argan tree is highly resistant to drought, fungi, parasites, and diseases and can live for more than two centuries, emanated the simple idea that it might contain highly valuable medicinal molecules. The commercial use of such a molecule would necessitate the cultivation of large quantities of argan trees by the argan forest dwellers who then would sell desired parts of the tree to pharmaceutical companies. If so then the sustainable development of the argan forest would be ascertained.

Plants of the family sapotaceae are known to contain high levels of saponins. These molecules are also found in many other botanical families growing in every continent and are known to possess all kind of pharmacological properties [10-14]. Rapidly, the search of new saponins from the argan tree became a Holy Grail chase. And indeed, several new saponins were discovered from various parts of the argan tree [15-17]. Although some were found to possess interesting anti-HIV activity [18,19], it rapidly became clear that the uncertainty, the time, and the challenges to develop a drug were incompatible with the time devoted to the argan forest rescue. There was also another challenge. What would happen if the "valuable molecule" was found in the argan tree root? Argan trees would never grow sufficiently rapidly to meet the suspected demand. This would have likely resulted in the accelerated deforestation of the argan forest. As a result, the search for an alternative output became necessary and argan oil emerged as the best alternative that possesses the necessary qualities to ensure the survival of the argan tree [20].

\subsubsection{Argan oil}

For centuries, Imazighen have used the kernels of the argan fruit stone as a source of edible and cosmetic oil. In the past, this copper-colored (edible oil) or golden colored (cosmetic) oil was exclusively prepared at household level following a multistep slow and tedious process involving hand-malaxing of an aqueous argan kernel dow [21]. As the shelflife of argan oil was short, it was prepared as needed. From a dietary standpoint, argan oil is highly valuable since it is rich in unsaturated fatty acids, polyphenols, sterols, and anti-oxidants. All of these compounds present protective properties for the cardiovascular system [22]. Argan oil is also used in cosmetics [23]. It has scar-healing properties, prevents skin ageing, and protects the hair shaft. However, until the 1980s, argan oil was a rather low-quality oil principally because of the uncertain bacteriological quality of the water used during its preparation. Besides, due to long walks associated with nut picking, producers were using argan nuts collected even among the feces of the goats. Argan oil prepared from this type of nuts presents unsatisfactory organoleptic properties [24]. Nevertheles, it was often mixed with 
"good argan oil" produced from nuts collected from the forest and sold alongside the dusty roads in Moroccan mountains roads to tourists for $\$ 2$ or $\$ 3$ a liter. Some would even sell colored corn oil in place of argan oil to buyers who cannot make the distinction.

The next challenge was to improve quality and to position argan oil into the highly lucrative vegetable oil market. Its dietary and cosmetic properties should justify a large-scale consumption that would, first necessitate to take good care of the trees and, second, to grow more trees. Collecting nuts is not damaging to the trees, and there is no risk of over-use as harvesting could occur. If the profits could be returned to the argan forest dwellers, their willingness to participate in this project would become stronger and this would ascertain the sustainable development of the argan forest. This required improving the scale of production.

Going from a family scale production to a (semi)industrial production has never been an easy task. In the argan oil case, it was necessary to produce, on a regular basis, large quantities of high quality argan oil. Then it was necessary to find methods to ensure high quality and to change the public perception on argan oil produced by villagers. This calls for creating customer loyalty to ascertain supply and quality of the oil market. Concurrently, this also implied ensuring accountability and equity and to avoid corruption and misappropriation of funds that would be generated from the market.

Traditionally, argan oil is exclusively prepared by Amazigh women. Consequently, they are the only one who master all the steps in its preparation. Therefore, the idea of using woman know-how spontaneously stood out as the only viable solution and led to the creation of woman cooperatives producing argan oil. However, the process involved in the traditional ways of preparing the oil was too slow and too rudimentary to envision a large-scale oil production. The use of screw-presses to replace the hand-malaxing step was then evaluated and turned out to be a real success. Not only traditionally prepared and press-extracted argan oils were shown to possess the same composition [25] but the oil extraction time was significantly reduced and the traditional use of water became unnecessary. This avoided the need for using water from unsafe sources such as wells. As a result, the major problem associated with bacteriological levels was addressed. The first technological problems being solved, the large-scale production of argan oil could begin, cooperatives becoming fully operative. Encouraged by the successful use of presses, gas burners were also used to roast kernels and prepare the edible-grade oil. Such burners allowed a precise control of the roasting time and temperature ascertaining a reproducible oil taste. To minimize the transport of the fruit, and of the women, and because as much of profits as possible had to return to the argan forest dwellers, it was decided to implant the cooperatives in villages located in the argan forest. This act was strongly symbolic since some of the selected locations got finally connected to the electricity network, a thing that had been waited for years. So even before the collection of the first drop of oil, argan forest dwellers could sense changes in their life.

In the argan forest, life is very family-oriented and most women have no regular jobs. They are often illiterate and constitute the weakest and vulnerable segments of the society. Thus, in the remote regions of the argan forest, organizing cooperatives also meant the first job offer ever. Women who accepted to participate in the cooperative program would get their first job and salary. This meant an increase of the family income as well. Of course, not every woman could be employed by the cooperative. Also, introduction of too much mechanization could mean a reduction in job numbers and a loss of authenticity for argan oil. Therefore, it was decided that fruit picking would remain manual 
and that the cooperatives would buy argan fruit from the argan forest dwellers. Cooperatives would only buy picked and pulped fruit in order to ensure that fruit collected from fecal of goats are not included. Because cooperatives were buying fruit, this meant that working in a cooperative was not mandatory to get some subsidies from the argan forest sustainable development project. Picking fruit, something that women and children were doing anyway to prepare argan oil at household level, and selling it to the cooperative swiftly emerged as a new and easy way to get some extra-income. Households would to pick more nuts and sell the excess to the cooperative. But cooperatives also offered more specific jobs to women: fruit de-pulping, kernel collecting, kernel roasting, kernel pressing, bottle filling, etc. In addition to a salary, teaching to read and write classes were also offered for free to cooperative members and classes in the basics of economics were offered to better educated women. During the first few months, women were suspicious. But later as woman cooperatives became successful, tourists and industries began to buy large quantities of oil, putting the woman cooperative business on the right track. As cooperatives grew, quality-control positions became available, and some of these positionswere filled by literate women. Hence, these women could make more money and get more prestigious jobs. In 2006, the total annual revenue of the woman cooperatives was close to $\$ 1$ million. In 2007 , argan oil was sold on major markets in the developed world and was quoted "the most expensive oil in the world", the price sometimes reaching $\$ 40$ for 100 $\mathrm{mL}$ of cosmetic oil.

The success of the sustainable development of the argan forest program cannot be simply evaluated in terms of argan oil sales. Year after year, collection of more nuts became necessary to satisfy the continuously growing demand in argan oil. The global production of argan fruit is approximately 350,000 tons ( 50 billion fruits) per annum, and hence overharvesting may not be a major concern. But for producers at the local level, this has some repercussions. In the souks (farmer markets), the average argan fruit and oil prices went up. Some speculative behavior was also noted and such questions as why selling argan oil at low price so long as it could have been sold at high price during the tourist period? Also, for the fruit pickers, it became necessary to walk farther and farther to collect the fruit. As argan fruit and oil prices rose, some worries appeared [26]. Could the sustainable development of the argan forest be synonymous with more difficulties for some dwellers of the argan forest? Could it mean that some segments of the local population would be deprived of argan oil? The woman cooperative program was expected to be a kind of social welfare but could it be possible that some people had been left out? Of course not every woman had become a cooperative member or had accepted to sell argan fruit to a cooperative. Very often, families who had decided to stay away from the cooperative program were also the most fragile and the less capable to capture the full benefits of this program. These families, for which argan oil was frequently the only source of lipid, were also the most badly hurt by the price increase and the relative scarcity of the fruit. Most of the time, women finally decided to join the cooperatives, sometimes on an irregular basis, but the solution came from argan forest dwellers. They suggested that argan trees should not be pulled out and more trees should be planted. It appears that the message had been received. 


\section{Conclusions}

Several factors should be considered to evaluate the success of the argan forest regeneration [27]. During the last three years, the area annually planted with young argan trees is around 2,000 ha. Because argan tree cultivation is not fully mastered yet (it is now understood that it is likely to be mycorrhizal dependent [28]), a large number of trees die during their first year. Therefore, important efforts are still necessary in this regards. However, the planted area is a reliable indicator to evaluate the population involvement in the argan forest rescue program. Unfortunately, it is not necessarily an indicator for its sustainable development. Indeed, whereas argan tree exists as a single species, genotypic variations exist, some trees producing more fruit than others, some fruit yielding more oil than others, and some nuts being easier to break than others... Therefore, it has been suggested that the cultivation of trees yielding large quantities of easy-to-break and oil-rich nuts should be favored [29]. Whereas the idea of producing more oil is commendable, this would also result in the transformation of the argan forest into an orchard and would result in a dramatic loss in terms of biodiversity. This could lead to a series of genetic erosion, the opposite of the sustainable development of the argan forest. Nowadays, this point is still debated.

Inevitably, the success of argan oil and its high price triggered fraudulent behaviors. Few cases of bribery have been reported and, among the newly created cooperatives, not all of them have implemented the rules as strictly as it was designed in the initial program. Even though analytical methods have now been designed to detect oil blending [30], protecting argan oil remains a prerequisite to protect the argan forest. Because argan forest rescue is dependent on a single produce, collapse of the argan oil market could mean the collapse of the argan forest rescue program as well. What would happen if argan trees could be cultivated elsewhere than in Southwestern Morocco? Recently argan oil has been granted with a certificate of geographical origin. Geographic indications are aimed at protecting produces that have a specific geographical origin and possess qualities that are specific to the place. Obviously, argan oil fully satisfies these requirements and, nowadays, only argan oil prepared from the fruit of trees naturally growing in Morocco should be sold on the markets. This measure should constitute the ultimate step allowing the sustainable development of the argan forest.

So far, the argan forest case is the most advanced example of successful sustainable development in Africa. More specifically, this case represents the only example in which a produce that was poorly known on its domestic market has found its place in the international market in less than fifteen years. Other similar projects are currently going on in Africa. The Sahelian Parklands project is one of the most ambitious project in West Africa and it involves the Governments of Burkina Faso, Niger, Senegal, and Mauritania. As for the argan forest case, a developed country (Norway in this case) is also supporting in the project. Other projects are also being developed in Uganda and Ghana. Interestingly, these projects share with the argan forest case the concept that sustainable development of lowlands can be achieved through the cultivation of an indigenous plant such as Vitellaria paradoxa, Balanites aegyptiaca, Parkia biglobosa, Tamarindus indica, etc.

Even though it is hazardous to draw conclusions based only on a single case, and as the sustainable development of the argan forest is still in its infant stage, some general guidelines can be drawn. The first one is that even in developing countries, with the initial financial help of richer countries, sustainable development might become a reality. If the support from rich countries is not an absolute 
necessity it often constitutes the spark that ignites the involvement of local authorities. The second lesson is that in the poorest parts of the world, well established plants/produces could play an important role for sustainable development. Indeed, cultivation of non-indigenous plants may affect the fragile economic and ecologic equilibrium existing in these remote rural areas. Also, the discovery of new marketable products is too uncertain to be a reliable basis for sustainable development. The third lesson is already well known: think globally, act locally. The success of argan oil is principally due to its oversea popularity and its elevated price in developed countries but the production remains local and benefits have always been returned to the cooperatives and distributed among women. This brings to the fourth lesson: full involvement of the native population is absolutely necessary. When infrastructure are underdeveloped, it can only be substituted with the local dweller goodwill and capturing this goodwill is the first step leading to success. Finally the fifth lesson is to diversify (if possible) the nature of the produces supporting the sustainable development. So far, this important point has not been fulfilled in the argan forest case, and only the geographic indication of argan oil has been helpful.

\section{Acknowledgements}

The write up of this manuscript was possible thanks to the collaborative project between "Université Mohammed V-Agdal" and "Université de Reims-Champagne Ardenne". The authors are thankful to both Universities.

\section{References}

1. Benzyane, M.; Blerot P.; Giot, P. Le Grand Livre de la Forêt Marocaine; Mhirit, O., Blerot P., Eds.; Mardaga: Sprimont, Belgium, 1999; p. 280.

2. Kenny, L.; De Zborowski, I. In Atlas de l'arganier et de l'arganeraie; IAV Hassan II: Rabat, Morocco, 2007; p. 190.

3. Huxtable, R.J. The pharmacology of Extinction. J. Ethnopharmacol. 1992, 37, 1-11.

4. Morton, J.F.; Voss, G.L. The Argan Tree (Argania sideroxylon, Sapotaceae), A Desert Source of Edible Oil. Econ. Bot. 1987, 41, 221-233.

5. Charrouf, Z.; Guillaume, D. Argan Oil, Functionnal Food, and the Sustainable development of the Argan Forest. Nat. Prod. Commun. 2008, 3, 283-288.

6. M'Hirit, O.; Benzyane, M.; Benchekroun, F.; El Yousfi, S.M.; Bendaanoun, M. L'Arganier. Une espèce fruitière-forestière à usages multiples; Mardaga: Sprimont, Belgium, 1998; p. 150.

7. Rosen, M.A. Energy Sustainability: A Pragmatic Approach and Illustrations. Sustainability 2009, 1, 55-80.

8. El Aich, A.; El Assouli, N.; Fathi, A.; Morand-Fehr, P.; Bourbouze, A. Ingestive Behaviour of Grazing Goats in the Southwestern Argan (Argania spinosa) forest of Morocco. Small Rumin. Res. 2005, 70, 248-256.

9. Alados, C.L.; El Aich, A. Stress Assessment of Argan (Argania spinosa (L.) Skeels) in Response to Land Uses across an Aridity Gradient: Translational Asymmetry and Branch Fractal Dimension. J. Arid Environ. 2007, 72, 338-349. 
10. Jiang, Y.L.; Oulad Ali, A.; Guillaume, D.; Weniger, B.; Anton, R. Triterpenoid Saponins from the Root of Sideroxylon cubense. Phytochemistry 1994, 35, 1013-1015.

11. Pires, V.S.; Guillaume, D.; Gosmann, G.; Schenkel, E.P. Saponins from Ilex dumosa, an Erva-Mate (Ilex paraguariensis) Adulterating Plant. J. Agric. Food Chem. 1997, 45, 1027-1031.

12. Massiot, G.; Lavaud, C.; Guillaume, D.; Le Men-Olivier, L.; van Binst, G. Identification and sequencing of Sugars in Saponins Using 2D H-1-NMR Spectroscopy. Chem. Commun. 1986, 19, 1485-1487.

13. Nait Mbark, A.; Guillaume, D.; Kol, O.; Charrouf, Z. Triterpenoid saponins from Herniaria fontanesii. Phytochemistry 1996, 43, 1075-1077.

14. Hostettmann, K.; Marston, A. Saponins; Cambridge University Press: Cambridge, UK, 1995; p. 548.

15. Charrouf, Z.; Wieruszeski, J.M.; Fkih-Tétouani, S.; Leroy, Y.; Charrouf, M.; Fournet, B. Triterpenoid Saponins from Argania spinosa. Phytochemistry 1992, 31, 2079-2086.

16. Oulad-Ali, A.; Kirchner, V.; Lobstein, A.; Weniger, B.; Anton, R.; Guillaume, D.; Charrouf, Z. Structure Elucidation of Three Triterpene Glycosides from theTtrunk of Argania spinosa. J. Nat. Prod. 1996, 59, 193-195.

17. El Fakhar, N.; Charrouf, Z.; Coddeville, B.; Leroy, Y.; Michalski, J.-C.; Guillaume, D. New Triterpenoid Saponins from Argania spinosa. J. Nat. Med. 2007, 61, 375-380.

18. Gosse, B.K.; Gnabre, J.N.; Bates, R.B.; Nakkiew, P.; Huang, R.C.C. Antiviral Saponins from Tieghemella heckelii. J. Nat. Prod. 2002, 65, 1942-1944.

19. Gosse, B.K.; Ito, Y.; Huang, R.C.C. Optimization of Active Saponin, Arganine C, for Microbicidal External Use. J. Liq. Chromatogr. Rel. Technol. 2004, 27, 1947-1953.

20. Charrouf, Z.; Harhar, H.; Gharby, S.; Guillaume, D. Enhancing the Value of Argan Oil is the Best Mean to Sustain the Argan Grove Economy and Biodiversity. Oleag. Corps Gras Lipides 2008, 15, 269-271.

21. Charrouf, Z.; Guillaume, D.; Driouich, A. The argan Tree, an asset for Morocco. Biofutur 2002, 220, 54-57.

22. Charrouf, Z.; Guillaume, D. Argan Oil: Occurrence, Composition and Impact on Human Health. Eur. J. Lipid Sci. Technol. 2008, 110, 632-636.

23. Dobrev, H. Clinical and Instrumental Study of the Efficacy of a New Sebum Control Cream. $J$. Cosmet. Dermatol. 2007, 6, 113-118.

24. Matthaüs, B.; Guillaume, D.; Gharby, S.; Haddad, A.; Harhar, H.; Charrouf, Z. Effect of Processing on the Quality of Edible Argan Oil. Food Chem. 2009, doi: j.foodchem.2009.10.023.

25. Hilali, M.; Charrouf, Z.; El Aziz Soulhi, A.; Hachimi, L.; Guillaume, D. Influence of Origin and Extraction Method on Argan Oil Physico-Chemical Characteristics and Composition. J. Agric. Food Chem. 2005, 53, 2081-2087.

26. Lybbert, T.J.; Barrett, C.B.; Narjisse, H. Market-based Conservation and Local Benefits: The Case of Argan Oil in Morocco. Ecol. Econ. 2002, 41, 125-144.

27. Belyazid, S. Studying a Multi-dimensional Problem Using System Dynamics The Case of Sustainability in the Semi-aridArgane Forest in Morocco. In The 20th International Conference of The System Dynamics Society, Palermo, Italy, 2002.

28. Nouaïm, R.; Chaussod, R. L'arganier et ses champignons. Pour la Science 2007, 360, 76-80. 
29. Nouaïm, R.; Echairi, A.; Kaaya, M.; Chaussod, R. Contribution à la domestication de l'arganier pour la production d'huile. Cahiers Agric. 2007, 16, 199-204.

30. Hilali, M.; Charrouf, Z.; El Azziz Soulhi, A.; Hachimi, L.; Guillaume, D. Detection of Argan Oil Adulteration Using Campesterol GC-Analysis. J. Am. Oil Chem. Soc. 2007, 84, 761-764.

(C) 2009 by the authors; licensee Molecular Diversity Preservation International, Basel, Switzerland. This article is an open-access article distributed under the terms and conditions of the Creative Commons Attribution license (http://creativecommons.org/licenses/by/3.0/). 